\title{
Phylogenetic Relationships of Australian Skinks of the Mabuya Group (Reptilia: Scincidae) Inferred from Mitochondrial DNA Sequences
}

\author{
Masanao Honda ${ }^{1 *}$, Hidetoshi Ota ${ }^{2}$, Mari Kobayashi ${ }^{1}$ and Tsutomu Hikida ${ }^{1}$ \\ ${ }^{1}$ Department of Zoology, Graduate School of Science, Kyoto University, \\ Sakyo, Kyoto, 606-8502 Japan \\ ${ }^{2}$ Tropical Biosphere Research Center, University of the Ryukyus, \\ Nishihara, Okinawa, 903-0213 Japan
}

(Received 25 June 1999, accepted 14 September 1999)

\begin{abstract}
Portions of two mitochondrial genes (12S and $16 \mathrm{~S}$ ribosomal RNAs) were sequenced to analyze the phylogenetic relationships of the Mabuya group from the Australian region (Corucia, Egernia and Tiliqua). Results indicated the monophyly of these genera and their divergence from Asian and African members of this group. This suggests that the diversity of the Mabuya group in the Australian region has increased through an endemic radiation, not through multiple colonizations from outside. Among the genera from this region, Corucia and Tiliqua were closest to each other. This result contradicts with those of the previous hypotheses on the basis of morphological and immunological data that, respectively, suggested closest affinities between Corucia and Egernia, and Egernia and Tiliqua. We suppose that the morphological characters exclusively joining Corucia and Egernia are actually in plesiomorphic state.
\end{abstract}

\section{INTRODUCTION}

Australia is noted for its unique fauna (e.g., Darlington, 1957). A number of systematists and biogeographers have attemped to reveal the origins and diversification processes of vertebrate lineages occurring in this region. Despite enthusiastic efforts and vigorous debates by those researchers, however, little consensus has yet been attained even on the most basisc issues relevant to the history of each lineage: Gondwanaland origin or Laurasian origin; current diversity as a consequence of mutiple colonization or in situ radiation (e.g., compare corresponding accounts by Cracraft [1974], Tyler [1979], and Cogger and Heatwole [1981]).

Recently a few molecular phylogenetic studies elucidated relationships of Australian and non-Australian taxa in particular lineages, giving useful clues to the solution of those problems (e.g., Fuller et al., 1998; Donnellan et al., 1999; Goerges et al., 1999). However, the number of lineages studied from such an approach are yet too few to allow any generalizations.

The scincid subfamily Lygosominae contains over 600 species of lizards distributed in Australia, as well as in temperate and tropical Asia, central and southern Africa, Madagascar and western Indian Ocean islands, southeastern North America, and central and South America includ-

\footnotetext{
* Corresponding author.
}

ing the Caribbean islands (Greer, 1970; Matsui, 1992; Zug, 1993). King (1973), on the basis of chromosomal data, recognized three distinct groups among Australian lygosomines. Greer (1979) demonstrated that these groups well correspond to three morphologically defined evolutionary lineages therein referred to as the Egernia, Eugongylus and Sphenomorphus groups. This view has been further confirmed by the subsequent systematic studies using chromosomal, morphological and immunological data for both Australian and non-Australian lygosomines (e.g., Hardy, 1979; Ota et al., 1988, 1991, 1995, 1996; Greer, 1989; Baverstock and Donnellan, 1990; King, 1990; Donnellan, 1991a,b). Most of these works have also revealed that chromosomal and morphological features of the Australian Egernia group are quite similar to those of a few non-Australian genera including the broadly distributed and highly diversified genus Mabuya. Thus, Greer's (1979) Egernia group is currently referred to as the Mabuya group together with Mabuya and other non-Australian relatives of this genus (Greer, 1989: but see Hutchinson [1981] for a different view as below).

The Mabuya group has a geographic range almost equal to that of the entire subfamily (Boulenger, 1887; Greer, 1970; Nussbaum and Raxworthy, 1994). Greer (1979) supposed that, within the Australian lygosomines, the Mabuya (= Egernia: see above) group was closer to the Eugongylus group than to the Sphenomorphus group. Such a relationship was confirmed by Hutchinson (1981) 
on the basis of immunological data, although he went so far as to even assume a sister relationship of the Australian members of the Mabuya group with the Eugongylus group, not with Asian Mabuya. With respect to the nonAustralian components of the Mabuya group, Honda et al. (1999b) recognized two distinct lineages for the Asian and African genera (i.e., Lygosoma and Mabuya subgroups) on the basis of molecular data. They, however, did not examine their relationships with the Australian genera of this group.

The Mabuya group from Australia (including Papua New Guinea and adjacent islands) consists of three genera, Corucia, Egernia and Tiliqua sensu lato (Greer, 1979). Their phylogenetic relationships are still controversial. Greer (1970), on the basis of morphological characters, argued for the closer affinity between Corucia and Egernia. On the other hand, results of immunodistance analysis by Hutchinson (1981) suggested the closest relationship between Egernia and Tiliqua.

We partially sequenced mitochondrial DNA for representatives of the Mabuya group from Australian region and analyzed resultant data together with sequence data for non-Australian members of this group phylogenetically. Our purposes are to elucidate the relationships among the Australian genera, and their affinity with nonAustralian members of the Mabuya group. We then discuss the source of diversity of this group in Australia accordingly

\section{MATERIALS AND METHODS}

Five lygosomine species were used. Voucher specimens are deposited in the herpetological collection of the Department of Zoology, Kyoto University (KUZ). Of these, four specimens (Corucia zebrata: KUZ 46906; Egernia frerei: KUZ 45196; Tiliqua gigas: KUZ 46926; and T. nigrolutea: KUZ 50018), representing the three Australian genera of the Mabuya group, were obtained from pet dealers in life or in fresh dead state, and the other (Carlia fusca: Guam, Mariana Islands, KUZ 27794) of the Eugongylus group were sampled in the field. Published sequences for representatives of the three putative lineages of the Asian/ African Mabuya group (Honda et al., 1999b: i.e., Lamprolepis smaragdina and Lygosoma bowringii of the Lygosoma subgroup; M. longicaudata of the Asian Mabuya subgroup; and M. quiquetaeniata of the African Mabuya subgroup) were also incorporated into the analysis. We selected Eumeces latiscutatus of the subfamily Scincinae, a possible closest relative of Lygosominae (Greer, 1970), as an outgroup to root the resultant dendrograms.

Recently, Cyclodomorphus (accommodating branchialis, casuarinae and maxima), Hemisphaeriodon (monotypic with gerrardii) and Trachydosaurus (monotypic with rugosus), once regarded as synonyms of Tiliqua, have been revalidated (Cogger, 1994). However, since immunologi- cal and morphological data indicate both monophyly and high genetic similarity of the above four genera (Hutchinson, 1981; Greer, 1989), designation of T. gigas and $T$. nigrolutea as the representatives of all four genera should involve any substantial error in the results of the analyses. Greer (1979) stated that Tribolonotus might belong to the Mabuya group. However, this genus is obviously a member of the Sphenomorphus group (Hutchinson, 1981).

DNA extraction, amplification and sequencing are described in detail elsewhere (Honda et al., 1999a,b). A part of mitochondrial $12 \mathrm{~S}$ and $16 \mathrm{~S}$ ribosomal RNA (rRNA) genes consisting of approximately 830 base pairs (bp) were amplified using the polymerase chain reaction (PCR; Saiki et al., 1988) with primers L1091, H1478, L2606, and H3056 (Kocher et al., 1989; Hedges et al., 1993).

Alignments for DNA sequences were determined based on maximum nucleotide similarity. We prepared a pairwise matrix of distance by Kimura's (1980) two-parameter model. The neighbor-joining (NJ) method (Saitou and Nei, 1987) was applied to infer relationships among taxa on the basis of the distance matrix. Degrees of supports for internal branches of each tree were assessed by 1,000 bootstrap replications (Felsenstein, 1985). These analyses were performed by use of Clustal W 1. 4 (Thompson et al., 1994). Maximum parsimony analysis (MP) was also performed using PAUP 3. 1. 1 with heuristic option (Swofford, 1993). No frequency bias was assumed for transition and transversion. The confidence was assessed by 1,000 bootstrap resamplings (Felsenstein, 1985). In both analyses, gap sites were excluded.

\section{RESULTS}

Aligned sequences from two mitochondrial genes are presented in Fig. 1. The 12S rRNA fragment consisted of 389 total sites, 159 of which were variable. For the $16 \mathrm{~S}$ rRNA fragment, there were 437 total aligned sites, 145 of which were variable. Intergeneric nucleotide replacements within Lygosominae varied from 63 bp (Corucia vs. Tiliqua nigrolutea) to $150 \mathrm{bp}$ (Lamprolepis or Lygosoma vs. Mabuya longicaudata). Nucleotide replacements within the Australian Mabuya group were observed from $63 \mathrm{bp}$ to $74 \mathrm{bp}$ (Egernia vs. T. gigas). Interspecific nucleotide replacements involved $44 \mathrm{bp}$ and $118 \mathrm{bp}$ in Tiliqua and Mabuya, respectively.

The NJ dendrogram derived from mitochondrial DNA distance matrix (not given) is shown in Fig. 2A. The ingroup portion of this dendrogram showed tetrachotomous clusters. First cluster was monotypic with Carlia. The second with $85 \%$ bootstrap support was composed of the Asian and African Mabuya, whereas the third, supported in all bootstrap iterations (100\%), consisted of the Lygosoma subgroup (as represented by Lamprolepis and Lygosoma). The four Australian representatives 

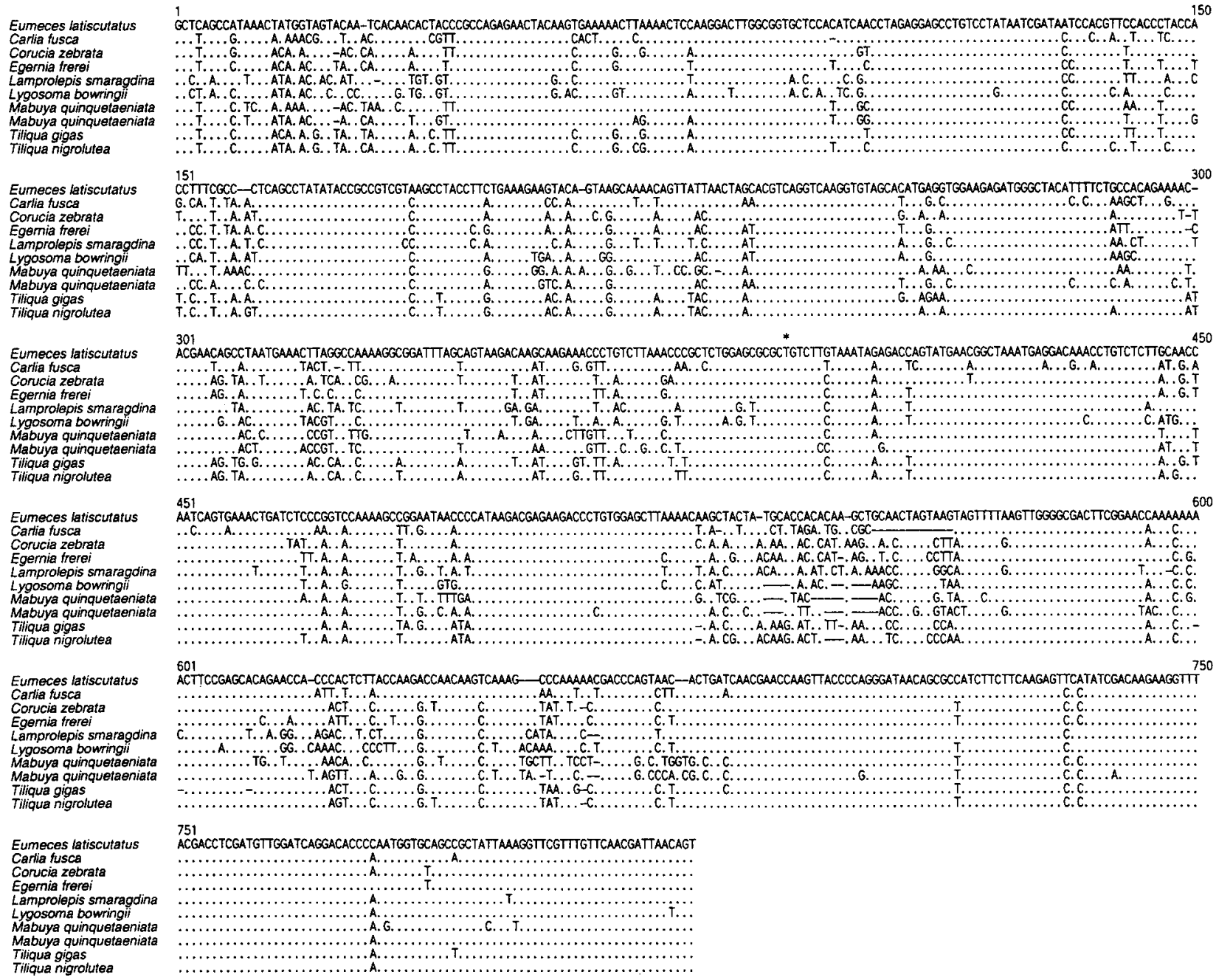

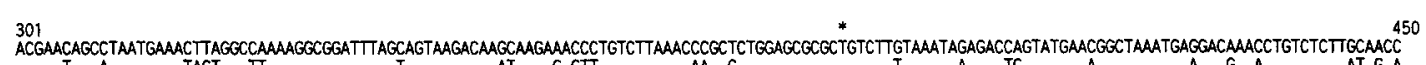
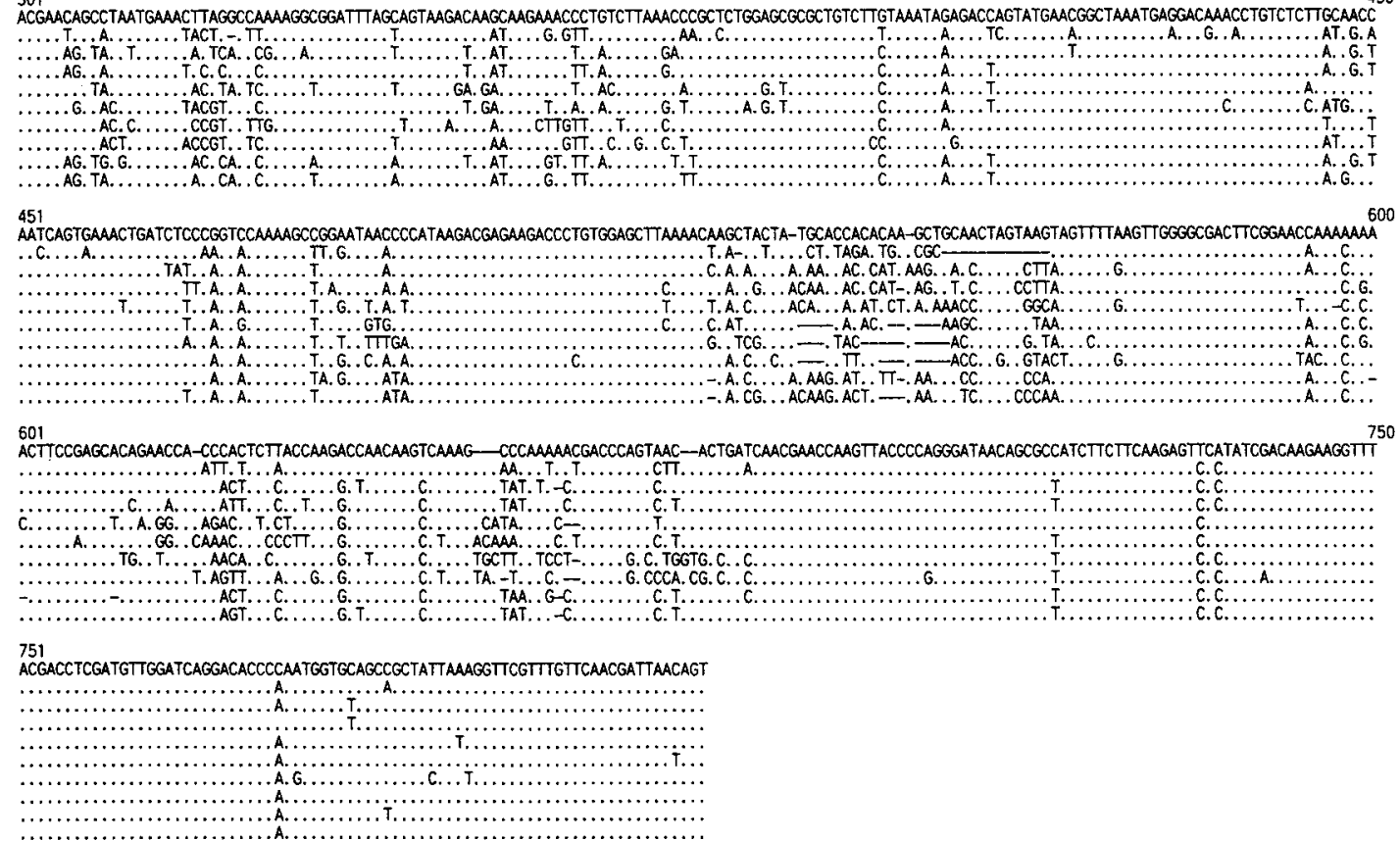

Fig. 1. Aligned sequences of a $826 \mathrm{bp}$ segment of the $12 \mathrm{~S}$ and $16 \mathrm{~S}$ rRNA genes. The initial $389 \mathrm{bp}$ in each row correspond to $12 \mathrm{~S}$ rRNA gene sequence. The 16S rRNA gene sequence begins at the asterisk. Dot indicates an identity with the first sequence; dash denotes a gap.
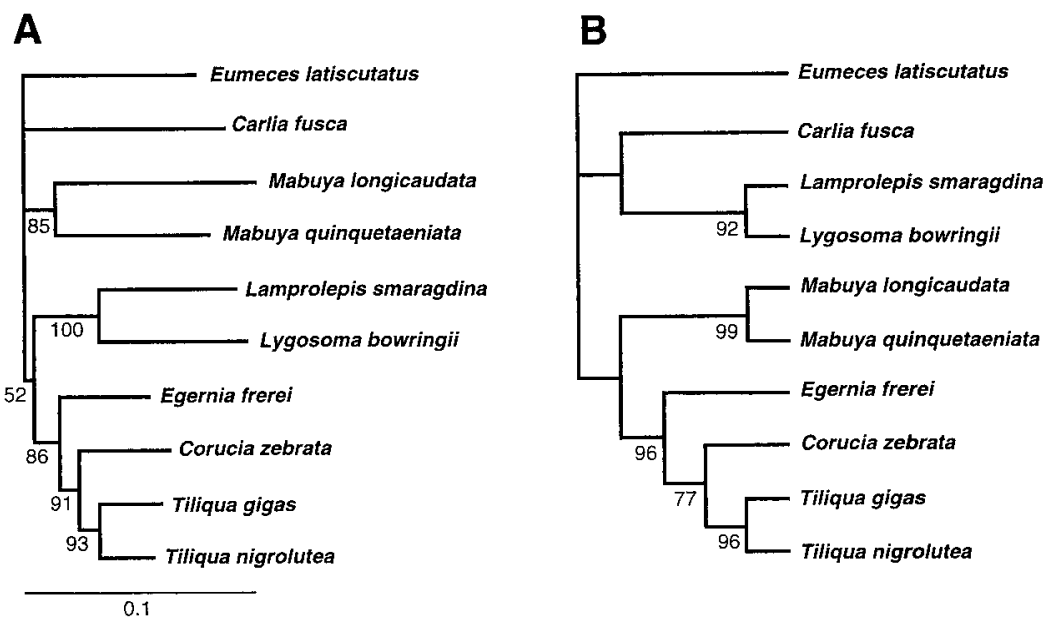

Fig. 2. (A) Neighbor-joining (NJ) dendrogram deriving from distance matrix from $12 \mathrm{~S}$ and $16 \mathrm{~S}$ rRNA sequence data. Numbers at branch indicate bootstrap proportions in 1,000 bootstrap pseudoreplications. Branches without BP values were not supported in $\geq 50 \%$ of the replicates. Bar equals 0.1 Kimura's two-parameter distance. (B) Maximum parsimony (MP) cladogram using heuristic option (618 steps, 176 bp informative under the condition of parsimony, consistency index $=0.58$ ). Branches without BP values were not supported in $\geq 50 \%$ of the 1,000 bootstrap replicates. 
were exclusively close to each other to constitute the fourth cluster with $86 \%$ support. Within this cluster, Egernia was located outside of the Corucia-Tiliqua subcluster $(91 \%)$. Congeneric samples of Tiliqua exclusively constituted lowest clusters (93\%).

Resultant cladogram of MP (Fig. 2B) showed no substantial inconsistency with the NJ dendrogram in terms of branching topology at the level more than $70 \%$ bootstrap iterations.

\section{DISCUSSION}

A few previous authors assumed the Australian members of the Mabuya group (= Egernia group) to be monophyletic on the basis of morphological and immunological data (Greer, 1979; Hutchinson, 1981). With respect to the Asian members of this group, Greer (1977) presumed that four phylogenetic lineages were independently derived from an Asian Mabuya-like ancestor. However, this view was negated by Honda et al. (1999b), who demonstrated the presence of two distinct lineages, the Lygosoma and Mabuya subgroups, within the Asian and African members of this group by the analysis of DNA sequence data. Phylogenetic relationships revealed in the present study indicate not only the monophyly of the Australian genera of the Mabuya group, but also their constituting the third major evolutionary lineage in this group, which may be referred to as the Egernia subgroup.

A number of morphological and karyological studies demonstrated a considerable similarity between the Egernia subgroup and non-Australian members of the Mabuya group (see above). On the other hand, within the Australian lygosomines, the Egernia subgroup and the Eugongylus group are supposed to be closer to each other than to the Sphenomorphus group (Greer, 1979; Hutchinson, 1981). Hutchinson (1981) further argued for the closer affinities of the former two sub/groups with each other against the non-Australian Mabuya group, whereas Greer's (1979) view on this regard remained equivocal. Unfortunately, we failed to obtain explicit evidence for this point, and this seems to reflect the almost concurrent radiation of all lineages involved (Fig. 2).

Greer (1970) surmised that Corucia and Egernia were exclusively closely related because both of these genera differ from other lygosomines in having palatine bones slightly separated along the midline of the secondary palate (palatine bones contacting medially in others). On the other hand, immunological data suggested a closer Egernia-Tiliqua affinity against Corucia (Hutchinson, 1981). Relationships proposed with high bootstrap values in the present results (i.e., closest relationship between Corucia and Tiliqua) support neither of those previous hypotheses. The widely separated palatines exhibited by most scincine genera is likely to represent a primitive character state in Scincidae, because Scincinae is obviously a basal group of this family (Greer, 1970, 1979). On the other hand, the extensive secondary palate formed by the close apposition of palatines is considered to be a synapomorphy of Lygosominae (Greer, 1986). Our results thus suggest that the common ancestor of the Egernia subgroup had slightly separated palatines, and that the medial contact of palatines in Tiliqua, apparently similar to the state in many other lygosomines, have independently evolved from the slightly separated state in Corucia. Hutchinson's (1981) analysis by micro-immunoelectrophoresis seems to suffer technically, because it at least partially depends on a subjective estimate of the intensity of precipitin arcs (Greer, 1986).

Distributions of Egernia and Tiliqua are largely confined to Australia, New Guinea and adjacent islands, except for T. gigas which ranges from New Guinea west to Sumatra (e.g., de Rooij, 1915; Cogger, 1994). According to the phylogenetic relationships inferred above, the three genera seem to have been derived from the common ancestor of the Egernia subgroup through endemic Australian radiation, rather than from multiple colonizations from outside, such as Southeast Asia, as is assumed for the Australian varanids (Fuller et al., 1998). Populations of $T$. gigas in the Sunda Archipelago of Indonesia and $C$. zebrata in the Solomons (McCoy, 1980) are thus considered as representing secondary dispersals.

We would like to thank A. E. Greer for detailed information of his work and useful suggestions, to Y. Yasukawa for the arrangement to obtain fresh dead material from pet dealers for free of charge, to M. Hasegawa for providing specimens of Carlia, and to K. Ishida and N. Takada for the laboratory assistance. Special thanks are due N. Satoh and members of his laboratory for a continuous support to our laboratory experiments. Experiments were also carried out using the facility of the Kyoto University Museum.

Our research was partially supported by Grants-in-Aid from the Japan Ministry of Education, Science, Sports and Culture (Basic Researches C-09839024 to H. Ota and C-10836010 to T. Hikida).

\section{REFERENCES}

Baverstock, P. B., and Donnellan, S. C. (1990) Molecular evolution in Australian dragons and skinks: A progress report. Mem. Queensland Mus. 29, 323-331.

Boulenger, G. A. (1887) Catalogue of the lizards in the British Museum (Nat. Hist.), Vol. 3. Taylor and Francis, London.

Cracraft, J. (1974) Continental drift and vertebrate distribution. Ann. Rev. Ecol. Syst. 5, 215-261.

Cogger, H. G. (1994) Reptiles and Amphibians of Australia, 5th ed. Cornell Univ. Press, New York.

Cogger, H. G., and Heatwole, H. (1981) The Australian reptiles: origins, biogeography, distributions patterns and island evolution. In: Ecological Biogeography of Australia (ed.: A. Keast), pp. 1331-1373, Dr. W. Junk Publ., Hague.

de Rooij, N. (1915) The Reptile of Indo-Australian Archipelago I: Lacertilia, Chelonia. E. J. Briil., Leiden.

Darlington, P. J., Jr. (1957) Zoogeography: The Geographical Dis- 
tributions of Animals. John Wiley \& Sons, New York.

Donnellan, S. C. (1991a) Chromosomes of Australian lygosomine skinks (Lacertilia: Scincidae) I. The Egernia group: C-banding, silver staining, Hoechst 33258 condensation analysis. Genetica 83, 207-222.

Donnellan, S. C. (1991b) Chromosomes of Australian lygosomine skinks (Lacertilia: Scincidae) II. The genus Lamprophlis. Genetica 83, 223-234.

Donnellan, S. C., Hutchison, M. N., and Saint, K. M. (1999) Molecular evidence for the phylogeny of Australian gekkonoid lizards. Biol. J. Linn. Soc 67, 97-118.

Felsenstein, J. (1985) Confidence limits on phylogenies: An approach using the bootstrap. Evolution 39, 783-791.

Fuller, S., Baverstock, P. B., and King, D. (1998) Biogeographic origins of goannas (Varanidae): A molecular perspective. Mol. Phyl. Evol. 9, 294-307.

Georges, A., Birrell, J., Saint, K. M., McCord, W., and Donnellan, S. C. (1999) A phylogeny for side-necked turtles (Chelonia: Pleurodia) based on mitochondrial and nuclear gene sequence variation. Biol. J. Linn. Soc. 67, 213-246.

Greer, A. E. (1970) A subfamilial classifications of scincid lizards. Bull. Mus. Comp. Zool. 139, 151-184.

Greer, A. E. (1977) The systematics and evolutionary relationships of the scincid lizard genus Lygosoma. J. Nat. Hist. 11, $515-540$.

Greer, A. E. (1979) A phylogenetic subdivision of Australian skinks. Rec. Aust. Mus. 32, 339-371.

Greer, A. E. (1986) Lygosomine (Scincidae) monophyly: A third, corroborating character and a reply to critics. J. Herpetol. 20, 123-126.

Greer, A. E. (1989) The Biology and Evolutions of Australian Lizards. Surrey Beaty and Sons, Chipping Norton.

Hardy, G. S. (1979) The karyotypes of two scincid lizards and their bearing on relationships in the genus Leiolopisma and its relatives (Scincidae: Lygosominae). New Zealand J. Zool. 6, $609-612$.

Hedges, S. B., Nussbaum, R. A., and Maxson, L. R. (1993) Caecilian phylogeny and biogeography inferred from mitochondrial DNA sequences of the 12S rRNA and 16S rRNA genes (Amphibia: Gymnophiona). Herpetol. Monogr. 7, 64-76.

Honda, M., Ota, H., Kobayashi, M., Nabhitabhata, J., Yong, H-S., and Hikida, T. (1999a) Phylogenetic relationships of the flying lizards, genus Draco (Reptilia, Agamidae). Zool. Sci. 16, $535-549$.

Honda, M., Ota, H., Kobayashi, M., Nabhitabhata, J., Yong, H-S., and Hikida, T. (1999b) Evolution of lygosomine skinks of the Mabuya group (Reptilia: Scincidae): A molecular perspective. Zool. Sci. (in press).

Hutchinson, M. N. (1981) The systematic relationships of the genera Egernia and Tiliqua (Lacertilia: Scincidae). A review and immunological reassessment. In: Proceeding of The Melbourne Herpetological Symposium (eds.: C. B. Banks and A. A. Martin), pp. 176-193, Zoological Board of Victoria, Melbourne.
Kimura, M. (1980) A simple method for estimating evolutionary rate of base substitutions through comparative studies of nucleotide sequences. J. Mol. Evol. 16, 116-120.

King, M. (1973) Karyotypic studies of some Australian Scincidae (Reptilia). Aust. J. Zool. 21, 21-32.

King, M. (1990) Chromosomal and immunogenetic data: A new respective on the origin of Australia's reptile. In: Cytogenetics of Amphibians and Reptiles (ed.: E. Olmo), pp. 153180, Birkhauser Verlag, Basel.

Kocher, T. D., Thomas, W. K., Meyer, A., Edwards, S. V., P\%o\%bo, S., Villablanca, F. X., and Wilson, A. C. (1989) Dynamics of mitochondrial DNA evolution in animals: Amplifications and sequencing with conserved primers. Proc. Nat. Acad. Sci. USA 86, 189-191.

Matsui, M. (1992) Systematic Zoology Vol. 9. Vertebrate IIb2, Reptilia. Nakayama Shoten, Tokyo (in Japanese).

McCoy, M. (1980) Reptiles of the Solomon Islands. Sheck Wah Tong Printing Press, Hong Kong.

Nussbaum, R. A., and Raxworthy, C. J. (1994) A new species of Mabuya Fitzinger (Reptilia: Squamata: Scincidae) from southern Madagascar. Herpetologica 50, 309-319.

Ota, H., Hikida, T., Matsui, M., and Hasegawa, M. (1988) Karyotype of a scincid lizard, Carlia fusca, from Guam, the Mariana Islands. Zool. Sci. 5, 901-903.

Ota, H., Hikida, T., Matsui, M., and Mori, A. (1991) Karyotypes of two water skinks of the genus Tropidophorus (Reptilia: Squamata) from Borneo. J. Herpetol. 25, 488-490.

Ota, H., Hikida, T., and Hasegawa, M. (1995) Karyotypes of two lygosomine lizards of the genus Emoia (Squamata: Scincidae) from Malaysia and Micronesia. Russ. J. Herpetol. 2, 43-45.

Ota, H., Hikida, T., Matsui, M., Hasegawa, M., Labang, D., and Nabhitabhata, J. (1996) Chromosomal variation in the scincid genus Mabuya and its arboreal relatives (Reptilia: Squamata). Genetica 98, 87-94.

Saiki, R. K., Gelfand, D. H., Stoffel, S., Scharf, S. J., Higuchi, R., Horn, G. T., Mullis, K. B., and Ehrlich, H. A. (1988) Primerdirected enzymatic amplification of DNA with a thermostable DNA polymerase. Science 239, 487-491.

Saitou, N., and Nei, M. (1987) The neighbor-joining method: A new method for reconstructing phylogenetic trees. Mol. Biol. Evol. 4, 406-425.

Swofford, D. L. (1993) Users Manual for PAUP 3.1: A Phylogenetic Analysis using Parsimony. Illinois Natural History Survey, Champain, Illinois.

Thompson, J. D., Higgins, D. G., and Gibson, T. J. (1994) CLUSTAL W: Improving the sensitivity of progressive multiple sequence alignment through sequence weighting, position specific gap penalties and weight matrix choice. Nucl. Acids Res., 22, 4673-4680.

Tyler, M. J. (1979) Herpetolofaunal relationships of South America with Australia. Mus. Nat. Hist., Univ. Kansas Monogr. 7, 73-106.

Zug, G. R. (1993) Herpetology. Academic Press, San Diego. 